전신 상태와 암의 중증도에 따른 대장암 환자의

마취 진료비 변이 분석

\author{
송주영' · 김지만 ${ }^{1}$ 신재용 ${ }^{2}$ 이상규 ${ }^{1}$ 김태현 ${ }^{1} \cdot$ 오은환 $^{3}$ \\ 김시진 ${ }^{4} \cdot$ 홍성진 ${ }^{5} \cdot$ 이기영 ${ }^{4}$
}

${ }^{1}$ 연세대학교 보건대학원, ${ }^{2}$ 연세대학교 의과대학 예방의학교실, ${ }^{3}$ 협성대학교 보건관리학과, ${ }^{4}$ 연세대학교 의과대학 마취통증의학교실, ${ }^{5}$ 가톨릭대학교 의과대학 마취통증의학교실

\title{
Analysis of variations in anesthesia cost according to severity of physical status and cancer stage in colorectal cancer patients
}

\section{Joo Young Song', Ji Man Kim¹, Jaeyong Shin'², Sang Gyu Lee', Tae Hyun Kim ${ }^{1}$, Eun Hwan $\mathrm{Oh}^{3}$, Sijin $\mathrm{Kim}^{4}$, Sung Jin Hong ${ }^{5}$, and Ki-Young Lee ${ }^{4}$}

Received February 13, 2018

Revised 1st, April 2, 2018

2nd, May 4, 2018

3rd, May 18, 2018

Accepted May 23, 2018

\section{Corresponding authors}

Ki-Young Lee, M.D., Ph.D.

Department of Anesthesiology and

Pain Medicine, Yonsei University

College of Medicine, 50-1 Yonsei-ro,

Seodaemun-gu, Seoul 03722, Korea

Tel: 82-2-2228-2421

Fax: 82-2-2227-7897

E-mail: kylee504@yuhs.ac

\section{ORCID}

http://orcid.org/0000-0003-4893-3195

Sung Jin Hong, M.D., Ph.D.

Department of Anesthesiology, Pain and Critical Care Medicine, College of Medicine, The Catholic University of Korea, 10 63-ro, Yeongdeungpogu, Seoul 07345, Korea

Tel: 82-2-3779-1097

Fax: 82-2-783-0368

E-mail: hongs@catholic.ac.kr

\section{ORCID}

http://orcid.org/0000-0001-9353-2644
${ }^{1}$ Graduate School of Public Health, Yonsei University, ${ }^{2}$ Department of Preventive Medicine, Yonsei University College of Medicine, Seoul, ${ }^{3}$ Department of Health Management, Hyupsung University, Hwaseong, ${ }^{4}$ Department of Anesthesiology and Pain Medicine, Yonsei University College of Medicine, ${ }^{5}$ Department of Anesthesiology, Pain and Critical Care Medicine, The Catholic University of Korea, Seoul, Korea

Background: Since the late 2000s, the number of anesthesia performed has increased yearly. However, there has not been research into the appropriate cost of anesthesia based on the difficulty of anesthesia performed, the number of medical personnel participated, and materials administered for anesthesia. The purpose of this study was to analyze the variations in anesthesia cost according to severity of their physical status and cancer stage in patients who had undertaken colorectal cancer surgeries.

Methods: In order to analyze the cost of anesthesia for colorectal cancer surgery, we used Electronic Data Interchange data from 2011 to 2012 of the three superior general hospitals in Seoul. Colorectal cancer codes were limited to seven codes included in the cancer screening statistics of the Health Insurance Review and Assessment Service. Based on these data, a frequency analysis and a multiple linear regression analysis were performed.

Results: There was no variation in the cost of anesthesia according to gender and age. However, the ASA physical status (PS) class and the cancer stage variables were confirmed to modify the anesthesia cost.

Conclusions: These study imply that there is a difference in the technology used for anesthesia by medical personnel as well as the anesthesia related materials used according to the ASA PS and the cancer stage among patients having the same disease.

Keywords: Anesthesia; Colorectal surgery; Cost.

This is an Open Access article distributed under the terms of the Creative Commons Attribution Non-Commercial License (http://creativecommons.org/licenses/by-nc/4.0) which permits unrestricted non-commercial use, distribution, and reproduction in any medium, provided the original work is properly cited. 


\section{서 론}

2000년대 후반부터 마취 시술 건수는 해마다 증가하는 추세 를 보이고 있다[1]. 이러한 실정에 비해 마취 시술의 난이도, 마 취 시술 관련 투입 인력, 마취 시술 관련 투입 재료 등을 고려한 마취 진료비 적정성에 대한 논의는 이루어지지 않고 있다. 총 마 취 시술 건수는 2009년 859만건을 시작으로 2010년 930만건, 2011년 943만건, 2012년 975만건, 2013년 950만건으로 증가 하는 추세를 보이고 있음에도 불구하고[2], 마취 시술 증가에 상 응하는 마취 진료비 수가 체계 현실화에 대한 논의는 활발하게 이루어지지 않았다. 또한, 마취 시술이 증가함에 따라 사회적으 로 마취 관련 안전과 질 관리에 대한 우려가 지속적으로 제기되 고 있다[3]. 마취와 관련한 의료사고는 중증인 경우가 많고, 내시 경 시술 등의 증가로 진정 마취를 경험하는 환자가 많아지면서 사회적 문제로 제기되고 있다[4].

마취 방법의 선택은 수술을 위해 요구되는 조건들을 최적으 로 만족시키는 방향에서 마취과 의사, 외과 의사, 환자의 합의 에 의해 결정된다. 마취 방법의 선택에 있어 가장 중요한 요인 은 수술의 종류와 수술이 시행되는 신체 부위 등이다. 이 외에 마 취 시술 시행 시, 마취과 의사의 경험 및 기술, 환자의 선호도, 환 자의 전신질환(systematic disease)의 유무와 중증도, 연령 등 이 마취 방법의 선택에 중요한 영향을 미친다[4]. 마취 시술 시, 이러한 요인들을 고려하는 이유는 환자의 여러 가지 상태 즉, 환자의 중증도(severe degree)나 위급도(emergency degree) 에 따라 마취 방법 및 시술에 차이가 존재할 수 있기 때문이 다. 이와 같은 이유에서 미국마취과학회(American Society of Anesthesiologists, ASA)에서는 수술 전 환자의 상태를 평가할 수 있는 체계인 ASA physical status classification system (ASA PS class)을 도입하였다. ASA PS class는 수술 전 환자의 중증도 나 위급상황에 따라 환자의 상태를 분류할 수 있는 체계로 사용 되고 있다. 또한, 해당 시스템은 환자의 상태를 파악하고 수술 환 자의 우선순위를 정하는데 사용된다[5].

마취 시술을 선택하고 결정하는 측면에 있어서 환자의 중증도 분류 체계인 ASA PS class를 비롯한 많은 요인들이 고려된다. 그 러나 이러한 요인들의 차이가 실제 마취 관련 건강보험요양급여 비용에는 반영되어 있지 않고, 급여 인정 범위가 제한적인 실정 이다. 건강보험요양급여비용에는 마취 시술에 대한 일반적 기준 만 제시되어 있을 뿐, 마취 시술의 난이도, 재료 등에 따른 행위 자의 구분과 마취 진료비의 적정성 검토는 이루어지지 않고 있 다. 특히, 포괄수가제의 전면 시행 및 신포괄수가제의 도입과 관 련하여 마취 시술과 같이 의사의 기술적인 부분이 포함되거나 환자의 중증도에 따라 시술의 난이도 및 재료 투입 등이 크게 차 이가 날 수 있는 분야에 대해 기존의 지불제도에서 반영하지 못 하는 문제점을 파악하고 개선 방향을 제시할 근거자료를 마련할
필요가 있다.

따라서 이 연구는 대장암 환자의 중증도에 따른 마취 진료비 현황과 변이를 분석하고 마취 진료비의 변이를 일으키는 요인을 파악하고자 하였다.

\section{대상 및 방법}

대장암 수술 환자의 마취 진료비 현황을 분석하기 위하여 수 도권 소재 상급 종합병원 세 곳의 진료 자료를 사용하였다. 그 중 진료일 기준 2011년 1월 1일부터 2012년 12월 31일까지의 전 자 진료 내역을 수집하여 사용하였다. 또한, 각 의료기관의 자료 중, 환자의 성별, 연령, ASA PS class, 대장암 병기, 급여 및 비 급여 등 모든 마취 관련 처방 내역을 활용하였다. 이와 관련하여 본 연구는 주 연구자가 속한 세브란스병원 연구윤리심의위원회 (Institutional Review Board) 승인(IRB no. 2-1040939-ABN-01-2016-404)을 받은 후 진행하였다.

연구 대상자인 대장암 수술 환자는 상병 기호(주상병 코드)에 건강보험심사평가원 대장암 통계에 포함되는 7가지 코드(C18: 결장의 악성 신생물, $\mathrm{C} 19$ : 직장구불결장 이행부의 악성 신생물,

Table 1. General Characteristics of the Study Subjects

\begin{tabular}{|c|c|}
\hline Variable & Patient \\
\hline \multicolumn{2}{|l|}{ Sex } \\
\hline Male & 1,053 (58.3) \\
\hline Female & $753(41.7)$ \\
\hline \multicolumn{2}{|l|}{ Age (yr) } \\
\hline$\leq 49$ & 210 (11.6) \\
\hline $50-59$ & $461(25.5)$ \\
\hline $60-69$ & $543(30.1)$ \\
\hline$\geq 70$ & $592(32.8)$ \\
\hline \multicolumn{2}{|c|}{ Length of stay (d) } \\
\hline$\leq 10$ & 899 (49.8) \\
\hline $11-20$ & $608(33.7)$ \\
\hline$\geq 21$ & 299 (16.6) \\
\hline \multicolumn{2}{|l|}{ Cancer stage } \\
\hline 0 & $31(1.7)$ \\
\hline 1 & 232 (12.9) \\
\hline 2 & $260(14.4)$ \\
\hline 3 & 285 (15.8) \\
\hline 4 & $135(7.5)$ \\
\hline Unspecified & $863(47.8)$ \\
\hline \multicolumn{2}{|l|}{ ASA PS class } \\
\hline 1 & 337 (18.7) \\
\hline 2 & $1,023(56.6)$ \\
\hline 3 & 414 (22.9) \\
\hline 4 & $32(1.8)$ \\
\hline Total & $1,806(100.0)$ \\
\hline
\end{tabular}

Values are presented as number (\%). ASA PS class: American Society of Anesthesiologists physical status classification. 
C20: 직장의 악성 신생물, D010: 결장의 제자리암종, D011: 직 장구불결장 이행부의 제자리암종, D012: 직장의 제자리암종, D013: 항문 및 항문관의 제자리암종) 중 하나라도 포함된 환자 로 제한하였다. 연구 대상자는 연령 제한 없이 상기 7 가지 코드 를 주진단으로 갖는 수술 전수를 대상으로 하였다.

분석대상 의료기관의 대장암 수술 환자는 총 2,532 명이었다. 이 중 동일 환자 중복 청구, 대장암 수술 외 진료 정보, 보험 분 류 오류 등 자료가 성실하게 기입되지 않은 726 명을 제외한, 총 1,806 명을 대상으로 분석을 시행하였다. 또한, 다중선형회귀분 석은 암 병기가 불분명 환자 863명을 제외한 943 명을 대상으로 시행하였다.

자료 분석은 각 처방 코드 중 대장암 수술로 발생하는 마취 진 료비를 분석대상으로 선정하였다. 또한, 마취통증의학과 전문의 지도하에 모든 Electronic Data Interchange 처방 코드를 마취 처방 건별 '행위, 재료, 약제, 검사'의 네 가지 카테고리로 분류하 였다. 이 중 병원별 상이한 비급여 진료 코드에 대해서도 마취통 증의학과 전문의의 분류 기준에 의거하여 산정하였다. 행위 진 료비의 경우 기도유지 관련 비용을, 재료 진료비의 경우 혈액제 제 관련 비용을 구분하여 분석하였다. 혈액제제 관련 비용은 약 제 비용에 포함시키지 않고 그 외 혈장 확장제와 각종 수액 재제 는 약제에 포함시켜 분석을 진행하였다. 위와 관련한 마취 진료
건별 세부 구분은 Appendix 1과 같다.

또한, ASA PS class의 경우에는 미국마취과학회에서 지정한 2010년 가이드라인에 준하여 분류하였고 암 병기는 미국 암 학 회에서 지정한 2010년 대장암 병기 분류 체계 가이드라인에 준 하여 분류하였다. 상기 내역들과 관련하여 마취와 관련된 모든 진료 내역은 마취통증의학과 소속 의사들이 처방한 것으로 가정 하여 분석하였다.

\section{통계분석}

분석방법은 첫 번째, 대장암 수술 환자의 일반적 특성 분석을 위하여 환자의 성별, 연령, 재원일수, 암 병기, ASA PS class에 따른 빈도 분석을 시행하였다.

두 번째, 대장암 수술 환자의 일반적 특성에 따른 총 마취 진 료 비용 항목에 대해 평균 비용, 표준편차, Quartile1 (Q1, 1분 위수), Quartile3 (Q3, 3분위수), coefficient of variation (CV, 변이 계수)를 산출하고 각 그룹 간의 진료비 차이를 확인하기 위 해 $t$-test와 ANOVA를 실시하였다.

세 번째, 대장암 수술 환자의 일반적 특성 중 암 병기 및 ASA PS class 변수 등에 대해 마취 시술 관련 행위, 재료, 약제, 검 사 4가지 항목의 평균 비용, 표준편차, Q1, Q3, CV를 산출하고

Table 2. Total Anesthetic Cost according to the Study Subjects

\begin{tabular}{|c|c|c|c|c|c|}
\hline Variable & Mean \pm SD & Q1 & Q3 & CV & $P$ value \\
\hline Sex & & & & & 0.053 \\
\hline Male & $1,058,318 \pm 375,298$ & 798,992 & $1,251,812$ & 0.35 & \\
\hline Female & $1,023,977 \pm 364,577$ & 759,596 & $1,229,427$ & 0.36 & \\
\hline Age (yr) & & & & & $<0.001$ \\
\hline$\leq 49$ & $1,056,554 \pm 429,791$ & 789,718 & $1,208,511$ & 0.41 & \\
\hline $50-59$ & $1,011,135 \pm 391,508$ & 723,328 & $1,241,909$ & 0.39 & \\
\hline $60-69$ & $996,073 \pm 334,501$ & 746,408 & $1,187,233$ & 0.34 & \\
\hline$\geq 70$ & $1,109,100 \pm 355,276$ & 860,486 & $1,286,806$ & 0.32 & \\
\hline Length of stay (d) & & & & & $<0.001$ \\
\hline$\leq 10$ & $871,929 \pm 234,061$ & 706,314 & 974,083 & 0.27 & \\
\hline $11-20$ & $1,156,440 \pm 387,011$ & 872,072 & $1,389,633$ & 0.33 & \\
\hline$\geq 21$ & $1,332,725 \pm 406,747$ & 1048,683 & $1,572,689$ & 0.31 & \\
\hline Cancer stage & & & & & $<0.001$ \\
\hline 0 & $1,131,107 \pm 346,817$ & 798,416 & $1,334,838$ & 0.31 & \\
\hline 1 & $883,613 \pm 241,106$ & 712,747 & $1,007,820$ & 0.27 & \\
\hline 2 & 1,041,231 $\pm 327,694$ & 808,807 & $1,234,876$ & 0.31 & \\
\hline 3 & $982,263 \pm 296,594$ & 789,357 & $1,141,536$ & 0.30 & \\
\hline 4 & $1,393,554 \pm 359,057$ & $1,126,497$ & $1,620,643$ & 0.26 & \\
\hline Unspecified & $1,050,529 \pm 399,698$ & 773,623 & $1,247,803$ & 0.38 & \\
\hline ASA PS class & & & & & $<0.001$ \\
\hline 1 & $923,974 \pm 300,036$ & 713,047 & $1,069,576$ & 0.32 & \\
\hline 2 & $1,032,805 \pm 364,374$ & 778,284 & $1,235,608$ & 0.35 & \\
\hline 3 & $1,154,354 \pm 404,485$ & 863,687 & $1,383,081$ & 0.35 & \\
\hline 4 & $1,238,215 \pm 354,930$ & 922,002 & $1,550,376$ & 0.29 & \\
\hline
\end{tabular}

Values are Korean won. CV: coefficient of variation (=SD/mean), ASA PS class: American Society of Anesthesiologists physical status classification. 
ANOVA 분석을 실시하였다.

마지막으로, 마취 진료비에 영향을 주는 변수를 파악하기 위 해 마취 시술 관련 행위, 재료, 약제, 검사 4 가지 항목의 평균 비 용에 대해 다중선형회귀분석을 실시하였다.

이외에도, 병원 간 변이를 확인하기 위하여 총 마취 진료 비용 에 따른 차이를 분석하였고 다중선형회귀분석에서 다중공선성 검정을 시행하였다. 또한, 연구 데이터의 분포도 확인을 위한 정 규성 검정을 시행하였다.

분석은 SAS 9.4 (SAS Institute Inc., USA)를 활용하였다.

\section{결 과}

분석대상 대장암 수술 환자의 성별은 남자 1,053명(58.3\%), 여자 753명(41.7\%)이었다. 연령은 70세 이상 환자가 592명 (32.8\%)으로 가장 많았으며, 60-69세 543명(30.1\%), 50-59 세 461명(25.5\%), 49세 이하 210명(11.6\%)이었다. 재원 일수 는 10 일 이하가 899 명(49.8\%)으로 가장 많았다. 분석대상 환자 의 ASA PS class는 class 1은 337명(18.7\%), class 2는 1,023명 (56.6\%), class 3은 414명(22.9\%), class 4는 32명(1.8\%)이었다 (Table 1).

연령별 평균 총 마취 진료비는 70 세 이상 환자가 가장 많았다 $(1,109,100 \pm 355,276$ 원). 재원 일수에 따른 평균 총 마취 진료 비는 21일 이상(1,332,725 $\pm 406,747$ 원), 11-20일(1,156,440 $\pm 387,011$ 원), 10 일 이하(871,929 $\pm 234,061$ 원) 순이었다. ASA PS class에 따른 평균 총 마취 진료비는 class 4 (1,238,215 $\pm 354,930$ 원), class 3 (1,154,354 $\pm 404,485$ 원), class 2 $(1,032,805 \pm 364,674$ 원), class 1 (923,974 \pm 300,036원) 순 이었다(Table 2).

암 병기 별 마취 시술 관련 행위 비용, 재료 비용, 약제 비 용, 검사 비용은 Table 3 과 같다. 마취 시술 관련 행위 비용 (775,064 $\pm 211,639$ 원), 재료 비용(245,310 $\pm 113,017$ 원), 약 제 비용(253,222 $\pm 86,175$ 원), 검사비용(119,959 $\pm 57,268$ 원) 모두 4 기에서 가장 많이 발생하였다. 암 병기 별 마취 시술 관련 행위 비용의 변이계수는 0.23-0.34로 큰 차이가 없었으 나, 검사 비용의 변이계수는 0.48-0.89 사이로 상대적으로 컸다 (Table 3).

ASA PS class에 따른 마취 시술 관련 행위 비용은 class 3에 서 가장 많았으며(631,161 $\pm 210,741$ 원), class 4 (609,863 \pm 161,273 원), class 2 (595,340 $\pm 190,148$ 원), class 1 (541,200 $\pm 161,621$ 원) 순이었다. 행위 비용을 제외한 마취 시술 관련 재료 비용, 약제 비용, 검사 비용은 class 4 에서 가장 많았으며, class 1 에서 가장 적었다. 마취 시술 관련 행위 비용의 변이계수 는 0.26-0.33였으나, 검사 비용의 변이계수는 0.45-1.07로 상대 적으로 컸다(Table 4).

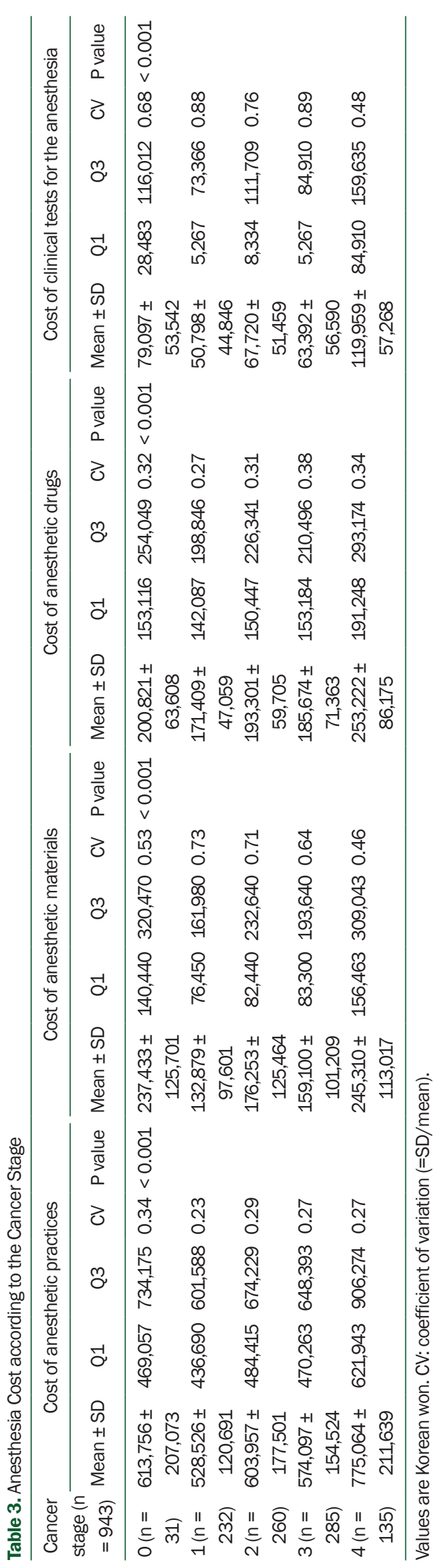




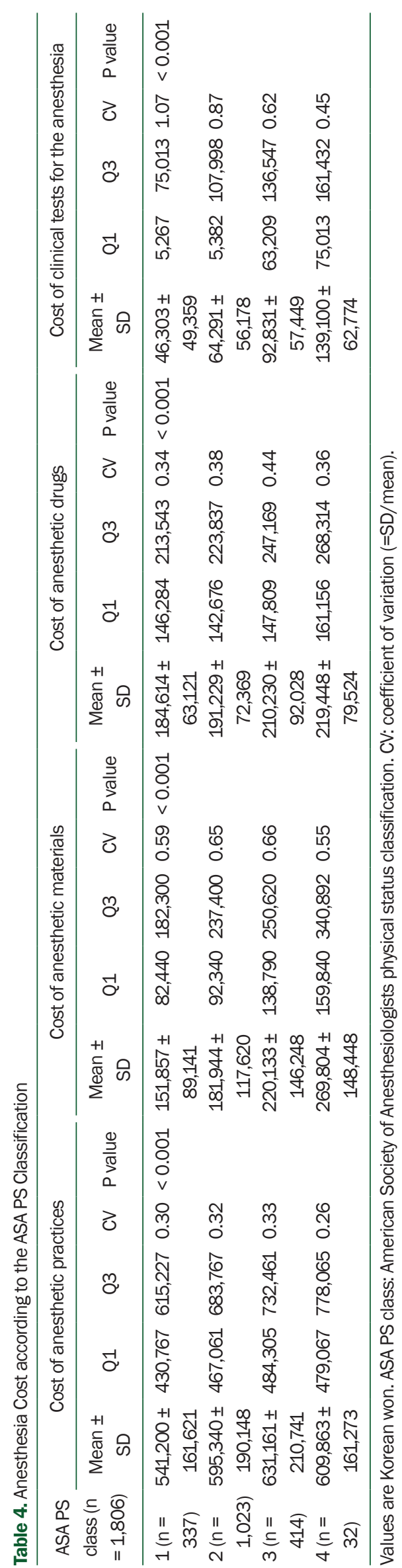

마취 진료비에 영향을 주는 요인을 파악하기 위한 선형회귀분 석 결과, 마취 시술 관련 행위 비용은 암 병기의 경우 4 기에서 0 기와 비교하여 143,350 원 더 많이 발생하였다(P < 0.001). ASA PS class에 따른 마취 시술 관련 행위 비용은 통계적으로 유의하 지 않았다. 마취 시술 관련 재료 비용은 ASA PS class 1 과 비교 하여 class 3은 38,026원(P < 0.001), class 4에서는 100,746 원 더 많이 발생하였다(P < 0.001). 마취 시술 관련 약제 비용 은 암 병기 0기보다 4 기에서 42,853원 더 많았다(P = 0.001). 마 취 시술 관련 검사 비용의 경우, 암 병기 0기와 비교하여 4 기에 서 36,317원 더 많이 발생하였다(P < 0.001). ASA PS class에 따른 마취 시술 관련 검사 비용은 class 1 과 비교하여 class 2, 3, 4에서 각각 9,229원(P = 0.022), 34,219원(P < 0.001), 67,330 원 더 많이 발생하였다(P < 0.001). 또한 마취 시술 관련 행위 비용, 재료 비용, 약제 비용, 검사 비용 모두 재원 일수가 늘어날 수록 증가하였다(Table 5).

또한, 의료기관 간 존재할 수 있는 마취 진료 비용 및 설명 변 수들의 분포 차이 확인을 위한 분석에서 통계적으로 유의한 차 이는 존재하지 않았다( $(\mathrm{P}=0.364)$. 다중선형회귀분석과 관련하 여 실시한 다중공선성 검정에서는 설명 변수들 간의 상관관계가 관측되지 않았다.

\section{고 찰}

이 연구는 대장암 환자의 중증도에 따른 총 마취 진료비, 마 취 시술 관련 행위 비용, 재료 비용, 약제 비용, 검사 비용의 변이 를 분석하고 그 차이를 확인하였다. 국내외적으로 대장암 환자 의 마취 진료비에 대한 선행연구가 드물고, 선행 연구들은 진료 비보다 ASA PS class를 통한 치료 결과 예측에 관한 연구[5-7]가 주로 이루어졌다. 그러므로 이 연구의 결과와 선행연구 결과를 비교하는 것은 한계가 있으나, 충분한 수의 연구 대상자를 분석 하였기 때문에 다음과 같은 시사점을 제시할 수 있다.

총 마취 진료비는 남성 평균 $1,058,318$ 원, 여성 평균 $1,023,977$ 원이었다. 연령별 평균 총 마취 진료비는 70 세 이상 환자가 $1,109,100$ 원으로 가장 많았으며, $60-69$ 세 환자는 996,073원으로 가장 낮았다. 총 마취 진료비는 환자의 중증도를 반영하는 ASA PS class가상승할수록 증가하였다.

다중선형회귀분석 결과, 성별과 연령에서는 마취 시술 관련 행위, 재료, 약제, 검사비의 변이가 발생하지 않았는데, 이러한 결과는 성별과 연령에 따른 진료비의 차이가 없었던 선행연구와 $[8,9]$ 일치한다. 그러나 재원 일수 변수에서는 선행연구와[10] 마 찬가지로 재원 일수의 증가에 따라 진료비의 변이가 존재하였 다. 암 병기의 경우 stage 1-3기에 비하여 stage 4에서 마취 시 술 관련 행위, 약제, 검사 비용에서 진료비의 변이가 존재하였다. ASA PS class의 경우 마취 시술 관련 재료, 검사 항목에서 ASA 


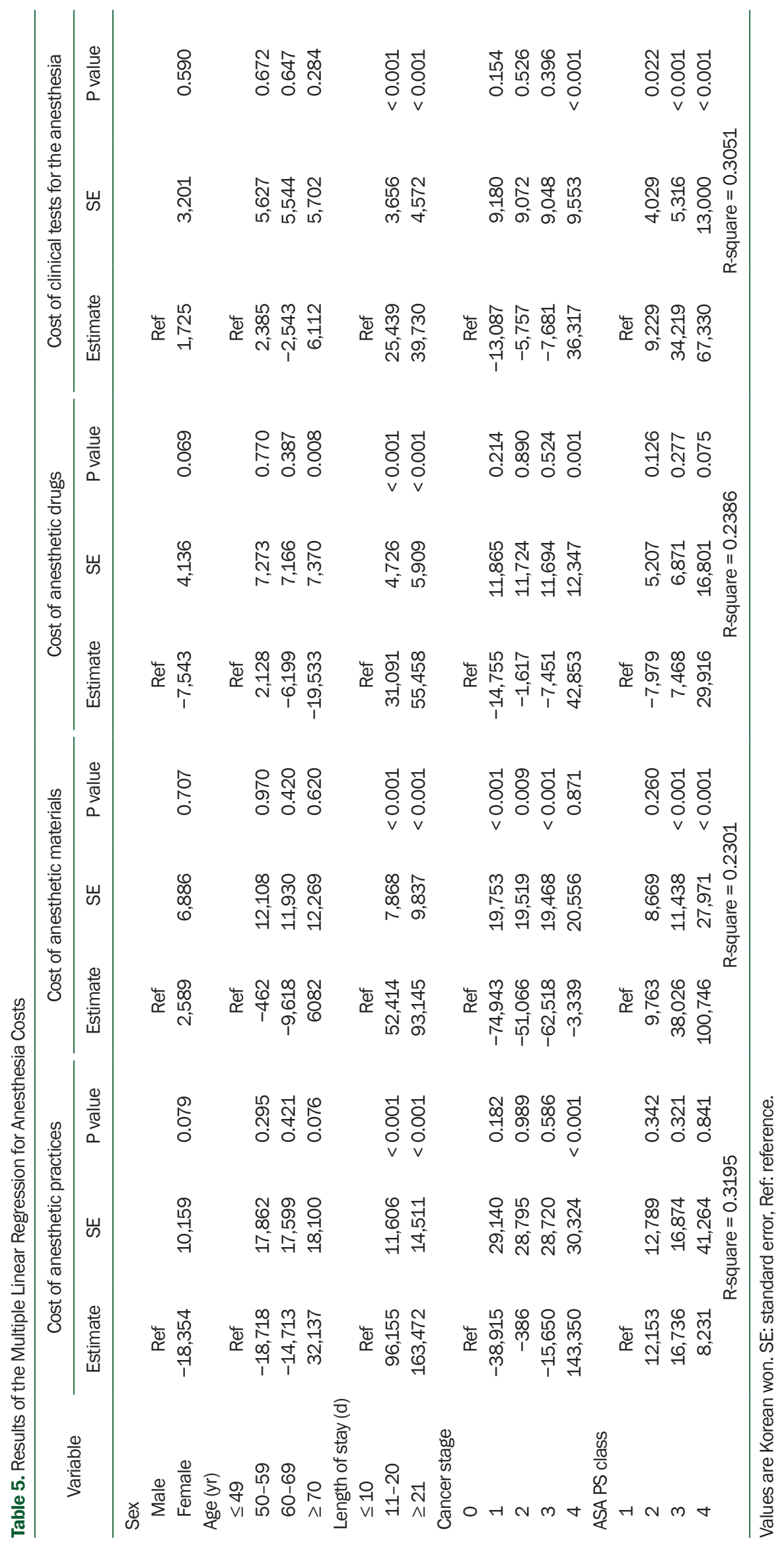


PS class가 1인 그룹에 비해 ASA PS class가 3, 4에 해당하는 그 룹에서 재료와 검사 비용이 많이 발생하였다. 선행연구에서는 [11] 진료비 변이를 일으키는 요인을 확인할 수 없었으나, 이 연 구에서는 마취 시술 관련 재료 및 검사비에서 변이가 발생하는 것을 확인하였다. 성별과 연령에서 마취 시술 관련 비용의 변이 가 발생하지 않았으나, ASA PS class 3, 4에서 재료와 검사 비용 의 변이가 발생한 것은 중증도가 높은 환자에게 재료와 검사의 처방이 많아 변이가 발생하는 것으로 추정된다. 또한, 이러한 마 취 시술 관련 재료 및 검사비의 차이가 행위 비용에서는 나타나 지 않았는데, 이는 행위 시술과 관련한 비용은 모든 환자에서 동 일하게 1 번씩 생성되기 때문이라고(시간 초과 가산료 제외) 유추 할 수 있다.

위 다중선형회귀분석 결과는 다음과 같은 두 가지 시사점을 나타낸다. 첫째, 마취 시술 관련 행위 비용은 ASA PS class에 따 라 유의한 차이가 없었으나 진행된 암 병기(stage 4 vs. stage 1-3)에 따라 유의한 진료비의 차이를 보였다. 이는 진행된 암 병 기가 높을수록 긴 시간이 소요되는 수술방법 선택의 결과로 볼 수 있고 이는 곧 마취 시간이 현 수가 체계에서 마취 시술 관련 행위 진료비의 주결정인자라는 것을 의미한다. 둘째, 상기 연구 결과 추후 '신포괄수가제' 도입 시 ASA PS class와 무관하게 총 마취 비용이 한 가지 항목으로 묶일 경우, 증가되는 마취 시술 관 련 재료 및 검사비용으로 인해 상대적으로 마취 시술 관련 행위 비용이 감액될 수 있음을 의미한다.

마취 시술 관련 행위 비용을 제외한 마취 시술 관련 재료, 검 사 비용은 중증도가 상승함에 따라 증가하는데 이는 환자의 상 태에 따라 투입되는 인력의 기술이나, 재료 등에서 차이가 있을 수 있음을 의미한다. 그러나, 현행 수가체계의 경우 마취 분야의 특수성을 감안하지 못하고 있는 실정이다. 마취 분야에서 해당 분야의 특수성을 감안한 수가체계가 발전되지 못하는 원인으로 는 마취 분야의 몇 가지 문제점들이 언급된다. 많은 의료기관에 서 마취 전문인력 없이 마취가 이루어지고 있고[4] 마취 전문간 호사 제도가 존재하지만 수가 매우 적어 실효성이 미흡하며[12], 의과대학에서의 마취 관련 행동 및 교육이 충분하지 못하다는 지적이 있다[13]. 또한, 마취 관련 수가 지불 제도가 체계적으로 정해져 있지 않아 의료기관이 마취전문의의 고용을 지양하며 급 여 인정 범위가 제한적이고 실질적인 난이도, 투입 인력 등을 차 등화하지 못한다는 지적이 있다.

그러므로 현재 진료비 수가 체계에서 포괄수가제 확산 및 신 포괄수가제 도입과 관련하여서 신중한 접근이 필요하다. 일본의 Diagnosis Procedure Combination (DPC), 독일의 GermanDiagnosis Related Groups (G-DRG) 등과[14] 같이 마취 분야 의 특수성을 감안한 수가체계를 형성하기 위해서는 마취 시술의 난이도, 투입 인력, 재료 등을 보다 세분화하고 구체화시켜 국내 실정에 맞는 현실적인 수가 지불제도 시스템에 대한 후속적인
연구가 필요할 것으로 사료된다.

이 연구는 중증도에 따른 대장암 환자의 마취 진료비 변이를 파악하기 위해 ASA PS class와 암 병기 등을 고려하여 마취 시 술 관련 행위, 재료, 약제, 검사 비용을 분석하였다. 그러나 이 연 구는 몇 가지 제한점을 가지고 있다. 첫째, 병원의 대표성과 관련 하여 수도권 소재 상급 종합병원 세 곳에서 수집된 자료라 전체 병원을 대상으로 하지 못했다는 제한점이 있다. 둘째, ASA PS class에 관한 선행연구가 미비해 연구 결과의 비교나 참고가 어 렵다. 국내에서는 ASA PS class와 마취 진료비와 관련한 연구가 없다. 해외에서도 위험 예측 인자나 치료 결과 예측 기준으로 쓰 이는 등 마취 진료비와 관련된 연구가 없어, 이 연구의 결과를 비 교하여 고찰하는데 한계가 있다.

본 연구의 다중선형회귀분석 결과로 환자의 중증도를 반영하 지 못한다고 판단되는 성별이나 연령 같은 변수와 달리 환자의 위급도나 중증도를 나타내는 ASA PS class에서 마취 시술 관련 재료 및 검사비의 변이가 발생하는 것을 확인하였다. 마취 시술 관련 재료 및 검사비의 변이가 ASA PS class와 재원일수에서 발 생한다는 결과를 바탕으로 동일한 질환을 가진 환자군 내에서도 해당 환자의 상태에 따라 투입되는 의료 인력의 기술, 마취 시술 관련 재료 등에서 차이가 있음을 확인하였다. 일본의 경우 마취 수가는 DPC에 포함되지 않고 마취 곤란 환자와 그 이외의 경우 에 대해 구분되어 수가가 산정되고 있으며 마취 관리료가 따로 있다. 또한, 독일 G-DRG의 경우에도 마취가 수술의 한 부분으 로 포함되며 여러 가지 영역을 고려하여 수가 지급이 이루어진 다[4]. 그러나 우리나라의 경우, 현재 마취 관련 수가지불제도는 체계가 합리적으로 정해져 있지 않아 의료기관이 마취전문의의 고용을 지양하고 있다. 더불어 시술의 난이도, 투입 인력 등에 의 해 차등화 되어있지 않은 항목과 제한적인 급여 인정 범위 등으 로 인해 마취 분야에서의 특수성을 감안한 수가 체계가 정착되 지 않았다. 이에 대해 의료계 및 정부의 보다 현실화된 수가체계 의 공론화가 필요하며 이를 뒷받침해 줄 심도 깊은 후속적인 연 구가 필요한 것으로 사료된다.

\section{REFERENCES}

1. National Health Insurance Service, Health Insurance Review \& Assessment Service. 2013 Health insurance statistical yearbook. Health Insurance Review \& Assessment Service [serial on the Internet]. 2014 [2014 May 1]. Available from http://opendata. hira.or.kr/op/opc/selectStcPblc.do?sno=10415\&odPblcTpCd=0 $02 \&$ searchCnd=\&searchWrd=\&pageIndex $=1$.

2. Kim YS, KIM JM, Lee SG, Lee KY, Hong KH, Lee KH, et al. The state of anesthetic services in Korea: a national survey of the status of anesthesia provider in the 2011-2013 period. J Korean Med Sci 2016; 31: 131-8. 
3. Kwon MI. The analysis of 137 anesthesia-related adverse outcome cases in Korea. Korean J Anesthesiol 2004; 46: 83-90.

4. National Evidence based Healthcare Collaborating Agency (NECA). International comparative study of anesthesia management policy. National Evidence based Healthcare Collaborating Agency [serial on the Internet]. 2013 [2014 May 1]. Available from https://www.neca.re.kr/layl/program/S1T11C145/report/view. do?seq $=67$.

5. Wolters U, Wolf T, Stützer H, Schröder T. ASA classification and perioperative variables as predictors of postoperative outcome. Br J Anaesth 1996; 77: 217-22.

6. Shaikh MA, Jeong HS, Mastro A, Davis K, Lysikowski J, Kenkel JM. Analysis of the American Society of Anesthesiologists physical status classification system and Caprini risk assessment model in predicting venous thromboembolic outcomes in plastic surgery patients. Aesthet Surg J 2016; 36: 497-505.

7. Visnjevac O, Lee J, Pourafkari L, Dosluoglu HH, Nader ND, Kritchevsky S. Functional capacity as a significant independent predictor of postoperative mortality for octogenarian ASA-III patients. J Gerontol Ser A 2014; 69: 1229-35.

8. Kang KR. The analysis of change on medical costs and length of stay by the diagnosis-related group payment system: data from a general hospital [Master thesis]. Seoul: Korea Univ., 2010.

9. Jung YS. The study on the variation of medical expenses con- ducting of before and after DRG: centered on a general hospital [Master thesis]. Seoul: Hanyang Univ., 2003.

10. Lee ES. The analysis of change on medical fee per inpatient day and Influence factors of length of stay - focusing on diseases with high frequency [Master thesis]. Busan: Pusan Univ., 2013.

11. Ellimoottil C, Ye Z, Chakrabarti AK, Englesbe MJ, Miller DC, Wei JT, et al. Understanding inpatient cost variation in kidney transplantation: implications for payment reforms. Urology 2016; 87: 88-94.

12. Oh BJ, Sin SR, Kim IO, Lee GS, Gang GA, Go MS, et al. A study on the projected workforce of advanced practice nurses in Korea. Korean Nurses Association [serial on the Internet]. 2003 [2014 May 1]. Available from http://www.riss.kr/search/detail/DetailView.do?p_mat_type=1a0202e37d52c72d\&control_no=b50a51e b2f6d3dce7ecd42904f0c5d65.

13. Chang DJ, Ahn SW, Ahn JW, Kim JH. The current status of anesthesiology clerkship in Korea. Korean J Anesthesiol 2008; 55: 1906.

14. Moon SW, Kim JS, Lee YG, Hwang RI, Choi ID, Seo SR. Study on foreign health care system and health insurance system in 2008. National Health Insurance Service [serial on the Internet]. 2008 [2014 May 1]. Available from http://riss.kr/search/detail/DetailView.do?p_mat_type=d7345961987b50bf\&control_no=588993fa 0186580cffe0bdc3ef48d419. 